\title{
Immigration and Heterogeneous Labor A Labor Market Classification Based on Nonparametric Estimation
}

\author{
Markus Frölich* and Patrick A. Puhani ${ }^{\#}$ \\ * SIAW, University of St. Gallen; IZA, Bonn

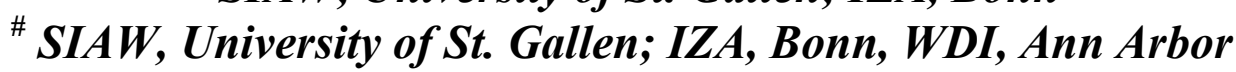

Internet Companion Paper to

Frölich, M. and P. Puhani (2004):

Developing an Immigration Policy for Germany on the Basis of a Nonparametric Labor Market Classification, Allgemeines Statistisches Archiv - Journal of the German Statistical Society 88: 1-22.

JEL classification: C14, J31, J61, J64, J68

Keywords: wage, unemployment, migration, rigidity, nonparametric regression

Markus Frölich

University of St. Gallen

SIAW, Room 103

Dufourstr. 48

CH-9000 St.Gallen

Switzerland

Phone: +41-71-224-2329

Fax: +41-71-224-2298

E-Mail:Markus.Froelich@unisg.ch

URL: www.siaw.unisg.ch/froelich
Patrick A. Puhani

University of St. Gallen

SIAW, Room 129

Dufourstr. 48

CH-9000 St.Gallen

Switzerland

Phone: +41-71-224-2341

Fax: +41-71-224-2298

E-Mail:Patrick.Puhani@unisg.ch

URL: www.siaw.unisg.ch/puhani 


\begin{abstract}
The most active immigration control policies in terms of skills in the western world exist in Australia and Canada, where point systems determine the aptitude of a candidate for immigration. These systems allocate a fixed number of points to a candidate's age, education and occupation, for example. In this paper, we present an alternative and arguably more flexible approach to immigration control, which is based on non-parametric estimation of recent labor market trends in narrowly defined labor markets. Our methodology is based on the identification of net demand shocks as well as wage rigidities in these heterogeneous labor markets.
\end{abstract}

Acknowledgements: We are grateful to Daron Acemoglu, Joshua Angrist, Herbert S. Buscher, Lars P. Feld, Simon Gächter, Ira Gang, Mark Killingsworth, Gebhardt Kirchgässner, Roger Klein, John Landon-Lane, Michael Lechner, Stephen Machin, Ruth Miquel, Michael Piore, Winfried Pohlmeier, Hans-Joachim Voth, two anonymous referees and seminar participants at Rutgers University, MIT, University of Konstanz, and University of St. Gallen for helpful comments.

Markus Frölich gratefully acknowledges financial support by the Swiss National Science Foundation (NSF 4043-058311). Patrick Puhani gratefully acknowledges financial support by the Volkswagen Foundation, Hannover. 


\section{Introduction}

The analysis of immigration and its effects on the labor market has received considerable interest in the economic literature. However, the reverse question on how immigration should be guided or regulated on the basis of the labor market situation in the host country has not enjoyed much attention. In this paper, we propose a methodology for assessing the immigration aptitude of particular labor markets. The approach is based on classifying labor markets according to whether they are increasing or decreasing in net demand and to whether they exhibit wage rigidities. To fully appreciate the heterogeneity of labor, we propose a nonparametric estimator as the basis for classification.

In general terms, immigration increases aggregate welfare of the host country if labor markets are competitive, because the gains to capital exceed the losses of native labor ( $c f$. Borjas, 1999a). However, the welfare effects of immigration are less clear in an economy with rigid labor markets, e.g. due to collective wage bargaining, or in the presence of a generous social security system as in many European countries (cf. Brecher and Choudri, 1987; Fuest and Thum, 2000; 2001; Schmidt, Stilz, and Zimmermann, 1994). But even with positive aggregate effects, immigration may be accompanied by a substantial income redistribution from labor to capital. If lump-sum taxes are not available, it is difficult to assess whether immigration is beneficial. Furthermore, in modern economies, labor is extremely heterogeneous (much beyond a simple distinction between skilled and unskilled) and different labor types are affected differently by the skill composition of the immigrants. It is thus not surprising that the distributional consequences of immigration fare prominently in public debates ( $c f$. Johnson, 1980). This controversy is also reflected in the restrictive immigration policies found in many countries. Also, selective immigration policies such as the 'points systems' in Australia, Canada, and New Zealand, which control immigrant flows on the basis of age, education, occupation etc. (cf. Antecol, Cobb-Clark, and Trejo, 2001; Bauer, 1998; Borjas, 1999b), are intended to contain immigration that might increase wage dispersion. By preferring mainly skilled labor, these regimes favor immigrants who pay more taxes and rely less on social transfers (see e.g. Borjas 1999b). However, if labor markets are non-competitive, selective immigration policies should also take account of potential wage rigidities.

Numerous empirical studies estimate impacts of immigration on wages and employments rates (for surveys see Friedberg and Hunt, 1995; Borjas, 1999a). However, these studies are not directly 
instructive for selective immigration policies, since they provide only highly aggregated results and do not take much account of heterogeneous labor (see Card, 2001, for an exception).

A natural basis for guiding selective immigration would be to prefer immigration in labor markets where demand is rising faster than supply. In such markets it is more likely that real wages will not fall in the face of increased competition from immigrants. Also, immigrants destined for such labor markets stand better chances finding a job instead of drawing social security benefits. On the other hand, labor markets plagued by rising unemployment should not be opened up to immigration, since the immigrants attached to these labor markets are more likely to become unemployed or cause unemployment among natives. Extending on these considerations, we propose a method for guiding a selective immigration policy by identifying labor markets suitable for immigration on the basis of recent labor market developments. In our companion paper (Frölich and Puhani, 2004), we apply this methodology to develop selective immigration recommendations for Germany.

Our particular focus in this paper is on the heterogeneity of labor. Compared to, for example, Altonji and Card, (1991), Bound and Johnson (1992), Katz and Murphy (1992), Murphy and Welsh (1992), Krueger and Pischke (1997), Card, Kramarz, and Lemieux (1999) or Kahn, (2000) we consider heterogeneity in greater detail. Distinctively, we suggest to estimate wage and unemployment risk developments by nonparametric regression for very specific labor markets defined by age, education, gender, occupation and sectoral background as well as region. Expected wages and unemployment risk are estimated by local linear and local logit regression. Nonparametric regression is often considered as unreliable in higher dimensions compared to parametric regression, due to the 'curse of dimensionality'. But, this argumentation is based on comparing nonparametric regression to a correctly specified parametric model. In most applications, however, the true regression curve is unknown, and recent Monte-Carlo results suggest that nonparametric regression with data-driven bandwidth selection outperforms misspecified parametric regression even in higher dimensions and is not much worse in case the parametric model is correctly specified.

Section 2 presents the theoretical framework and the strategy for identifying 'decreasing' and 'increasing' labor markets as well as wage rigidities. Section 3 outlines the nonparametric regression techniques, which provide the basis for our proposal for selective immigration control. We believe that our approach is more flexible than the point systems of Australia or Canada. We are aware that other factors may be important for immigration policy, like financing the pension system or legal 
necessities related to international agreements as provided by the European Union. Nevertheless, we believe that recent labor market trends should be a key ingredient to any selective immigration policy as they provide a more transparent and objectve criterion than most competitors, notably forecasts of future labor market developments. Forecasts are more subject to discussion than the measurement of past events. This is the reason why we focus our attention on recent labor market trends in this paper. Section 4 concludes.

\section{A Simple Model of the Labor Market with Heterogeneous Labor}

As a basis for reasoning in which labor markets immigration would be appropriate, we want to classify markets according to whether they are 'increasing' or 'decreasing' in 'net demand'. Furthermore, the existence of wage rigidities causing unemployment will come to bear when deciding about immigration. Markets where demand is increasing faster than supply and where real wages are rising are likely to absorb immigrants more easily than labor markets which experience rising unemployment and stagnant or falling real wages. By considering unemployment changes as an input into immigration control, we pay special attention to the (continental) European situation, where unemployment is an important political issue.

We propose an empirical strategy based on the supply-demand-institutions framework of Katz and Autor (1999). As in the studies by Nickell and Bell (1996) and Gottschalk and Joyce (1998), our approach uses unemployment as an indicator for quantity rationing in order to identify wage rigidities and net demand (supply) shocks. Suppose there are $L$ different heterogeneous labor markets, and let any particular labor market $l$ be characterized by a set of skills or characteristics. Let

$$
\begin{array}{ll}
D_{t}=D_{t}\left(\mathcal{W}_{t}, Z_{t}\right) & (L \times 1 \text { vector of labor demands }) \\
S_{t}=S_{t}\left(\mathcal{W}_{t}, Z_{t}\right) & (L \times 1 \text { vector of labor supplies })
\end{array}
$$

denote the labor demand and labor supply functions at time $t$, given the vector of wage rates $\mathcal{W}_{t}$ and a vector $Z_{t}$ of 'shift factors', which might affect labor demand and/or supply. These shift factors may include macroeconomic factors such as the business cycle, interest rates, technological change, the tax structure or changes in the educational composition as well as specific factors related to the labor 
market such as specific labor market regulations. Notice that $D_{t}$ and $S_{t}$ as well as $\mathcal{W}_{t}$ are vectors of dimension $L \times 1$ that contain demand, supply and wage rates for all markets, respectively. Hence demand and supply in any labor market $l$ depend on the wage rates in all labor markets. If labor markets are perfectly competitive and an equilibrium exists, wages $\mathcal{W}_{t}$ should clear all markets such that $D_{t}=S_{t}$. In this case, no unemployment would exist. On the other hand, if markets are imperfect, unemployment may occur through a number of reasons, either due to market frictions (e.g. incomplete information or transaction costs) or due to institutional reasons causing wage adjustment rigidities (e.g. unions, minimum wages, rigid pay scales). For immigration policy we are particularly interested in identifying wage rigidities and define the (hypothetical) unemployment rates $\mathcal{U}_{\text {rigid,t }}(L \times 1$ vector) as the unemployment rates that would be generated by the wage setting institutions in the absence of frictions:

$\mathcal{U}_{\text {rigid }, t}\left(\mathcal{W}_{t}, Z_{t}\right)=\frac{\left(S_{t}-D_{t}\right)}{S_{t}}=1-\frac{D_{t}\left(\mathcal{W}_{t}, Z_{t}\right)}{S_{t}\left(\mathcal{W}_{t}, Z_{t}\right)}$

Unemployment due to rigid wages is seen as a form of quantity rationing which may exist if wages are not allowed to settle at the market clearing rate (cf. Nickell and Bell, 1996; Gottschalk and Joyce, 1998; Puhani, 2003). In the presence of (additional) labor market frictions, however, the observed unemployment rates

$$
\mathcal{U}_{\text {observed }, t}=\varphi_{t}\left(\mathcal{U}_{\text {rigid }, t}, \gamma_{t}\right)
$$

are larger than the unemployment rates due to rigidities $\mathcal{U}_{\text {rigid,t }}$ and depend on factors $\gamma_{t}$ which influence the extent of labor market frictions. Since market frictions may be of different extent in different labor markets, $\mathcal{U}_{\text {rigid, } t}$ and thus the absolute level of rigidity is not identified. This precludes using observed unemployment rates as measures for the extent of labor market rigidities. Consequently, we identify changes in wage rigidities via concurrent movements in observed unemployment rates and observed wages over time. If this approach is applied to a period where unemployment is initially low but higher later, the identification of labor markets with changes in wage rigidities identifies rigidities in all labor markets which experienced negative net demand shocks. 
The main identifying assumption for detecting wage rigidities is that changes over time in the observed unemployment rate and the (hypothetical) rigid unemployment rate move in the same direction, which holds if there are no exogenous shocks to market frictions. Precisely, it is assumed that for each labor market $l$

$$
\operatorname{sgn}\left(\Delta_{t}^{t+\tau} \mathcal{U}_{\text {observed }}^{l}\right)=\operatorname{sgn}\left(\Delta_{t}^{t+\tau} \mathcal{U}_{\text {rigid }}^{l}\right)
$$

holds, where $s g n$ is the sign function, $\mathcal{U}_{\text {observed }}^{l}$ and $\mathcal{U}_{\text {rigid }}^{l}$ refer to labor market $l$, and $\Delta_{t}^{t+\tau} \mathcal{U}$ is the difference between $\mathcal{U}_{t+\tau}$ and $\mathcal{U}_{t}$. This assumption requires that any changes in the unemployment rate due to wage setting rigidities are not completely offset (or even overcompensated) by opposite movements in the frictional unemployment element. Yet, it is allowed that shocks in the rigid unemployment rate are mitigated by adjustments in frictional unemployment.

With this assumption, changes in observed unemployment rates identify the sign of the change in unemployment due to wage rigidities. Furthermore, changes in the rigid unemployment rate can be decomposed into an 'own-wage effect', 'cross-wage effects' and effects due to changes in the 'shift factors' $Z_{t}$ by using a Taylor series approximation:

$$
\Delta_{t}^{t+\tau} \mathcal{U}_{\text {rigid }}^{l} \approx \underbrace{\mathcal{U}_{\mathcal{W}}^{l, l} \cdot \Delta_{t}^{t+\tau} \mathcal{W}^{l}}_{\text {own wage effect }}+\underbrace{\sum_{j \neq l} \mathcal{U}_{\mathcal{W}}^{l, j} \cdot \Delta_{t}^{t+\tau} \mathcal{W}^{j}}_{\text {cross wage effects }}+\underbrace{\sum_{j} \mathcal{U}_{\mathcal{Z}}^{l, j} \cdot \Delta_{t}^{t+\tau} Z^{j}}_{\text {pure net supply shift effects }},
$$

where $\mathcal{U}_{\mathcal{W}}^{l, j}$ is the $(l, j)$-element of the Jacobian derivative of $\mathcal{U}_{\text {rigid }}$ with respect to the wage rates vector $\mathcal{W}_{t}$ and $\mathcal{U}_{\mathcal{Z}}^{l, j}$ refers to the corresponding element in the Jacobian derivative with respect to $Z_{t}$. Further, $\Delta_{t}^{t+\tau} \mathcal{W}^{l}$ is the change in the wage rate in labor market $l$ between times $t$ and $t+\tau$, and $\Delta_{t}^{t+\tau} Z^{l}$ is the change in $Z_{t}^{l}$. The first term on the right hand side of the approximation is the change in the unemployment rate in labor market $l$ brought about by changes in the wage rate in this market. The second term accounts for the impacts of changing wages in other labor markets on the unemployment rate in labor market $l$, and the third term incorporates the effects originating from changes in the shift factors. These latter two terms can be interpreted as shifts in the demand and supply curves due to changes in the wage structure and external factors, respectively, and can be summarized as a net supply shift, abbreviated as 


$$
\xi=\underbrace{\sum_{j \neq l} \mathcal{U}_{\mathcal{W}}^{l, j} \cdot \Delta_{t}^{t+\tau} \mathcal{W}^{j}+\sum_{j} \mathcal{U}_{\mathcal{Z}}^{l, j} \cdot \Delta_{t}^{t+\tau} Z^{j}}_{\text {net supply shift effects }} .
$$

Supposing further that labor supply and demand functions are well-behaved, such that the own-wage derivative $\mathcal{U}_{\mathcal{W}}^{l, l}$ is positive (increases in the wage $\mathcal{W}^{l}$ ceteris paribus lead to higher unemployment), the sign of the net supply shift in period $[t, t+\tau]$ can in most cases be inferred from the observed changes in the unemployment rate $\mathcal{U}^{l} \equiv \mathcal{U}_{\text {observed }}^{l}$ and the wage rate $\mathcal{W}^{l}$. Table 1 summarizes these results.

Table 1: Wage and Unemployment Changes, Net Supply Shifts and Immigration

\begin{tabular}{c|c|c|c}
\hline \hline & $\begin{array}{c}\text { Decreasing } \\
\text { unemployment } \\
\Delta_{t}^{t+\tau} \mathcal{U}^{l}<0\end{array}$ & $\begin{array}{c}\text { Constant } \\
\text { unemployment } \\
\Delta_{t}^{t+\tau} \mathcal{U}^{l}=0\end{array}$ & $\begin{array}{c}\text { Increasing } \\
\text { unemployment } \\
\Delta_{t}^{t+\tau} \mathcal{U}^{l}>0\end{array}$ \\
\hline $\begin{array}{c}\text { Increasing wage } \\
\Delta_{t}^{t+\tau} \mathcal{W}^{l}>0\end{array}$ & $\begin{array}{c}(7): \xi<0 \\
\text { weakly adjusting in } \\
\text { increasing market }\end{array}$ & $\begin{array}{c}(6): \xi<0 \\
\text { strongly adjusting in } \\
\text { increasing market }\end{array}$ & $\begin{array}{c}(1): \xi=? \\
\text { strongly rigid } \\
\text { (wage push })\end{array}$ \\
\hline $\begin{array}{c}\text { Constant wage } \\
\Delta_{t}^{t+\tau} \mathcal{W}^{l}=0\end{array}$ & $\begin{array}{c}\text { (8): } \xi<0 \\
\text { weakly rigid in } \\
\text { increasing market }\end{array}$ & $\begin{array}{c}(5): \xi=0 \\
\text { stable in a stable } \\
\text { market }\end{array}$ & $\begin{array}{c}\text { weakly rigid in } \\
\text { decreasing market }\end{array}$ \\
\hline $\begin{array}{c}\text { Decreasing wage } \\
\Delta_{t}^{t+\tau} \mathcal{W}^{l}<0\end{array}$ & $\begin{array}{c}\text { (9): } \xi=? \\
\text { converging } \\
\text { (wage pull) }\end{array}$ & $\begin{array}{c}(4): \xi>0 \\
\text { strongly adjusting in } \\
\text { decreasing market }\end{array}$ & $\begin{array}{c}\text { weakly adjusting in } \\
\text { decreasing market }\end{array}$ \\
\hline \hline
\end{tabular}

Note: Classification of labor markets according to observed changes in wage and unemployment rates. $\xi$ denotes the net supply shift effect (i.e. the sum of cross-wage effects and pure net supply effects). Lightly shaded markets $(6,7,8)$ appear able to integrate immigrants. Unshaded markets $(1,2,3,4,9)$ are less promising for absorbing immigrants. The case 'stable in a stable market' (darkly shaded) is undecided.

In markets where unemployment decreases and wages do not fall and in markets where wage increases are not accompanied by rising unemployment, the net supply shift effect $\xi$ is negative (markets (6), (7) and (8), lightly shaded in Table 1). These markets are called 'increasing' as demand grows faster than supply (at a perceived constant wage). Hence, they seem able to absorb an influx of immigrants without creating much socio-political tension. Immigration into these labor markets is recommended ( $c f$. Bauer, Lofstrom, and Zimmermann, 2000). 
On the other hand, markets where unemployment increases and/or wages decrease do not seem very suited to incorporate immigrants. The markets (2), (3) and (4) are characterized by a positive net supply shift $\xi$ (which is equivalent to a negative net demand shift) and are thus 'decreasing' in demand. Also immigration into markets classified as strongly rigid (1) and converging (9) in Table 1 is not recommended, although the sign of the net supply shift is undecided in both cases. In case (1) wages rise, but so does unemployment, indicating a strong rigidity (wage push) in the wage setting process. If immigrants enter as outsiders into these markets, their employment chances may be bleak. In case (9) wages fall together with unemployment, indicating a convergence towards competitive wage setting. Since immigration might further increase the downward pressure on wages, immigration into such markets might increase socio-political tension. Finally, in labor markets where neither wages nor unemployment change, case (5), the net supply shift is zero and no recommendation can be given. Although additional competition in these markets may lower wages of residents, it is unclear whether the labor market effects of immigration on residents are significantly large (see the studies cited in the Introduction), nor what the dynamic effects of immigration are. A society open to immigration would probably welcome immigrants to these labor markets, whereas a society less open to immigration may want to prevent immigration in this case. The classification in Table 1 thus provides an indication as to which immigrants might be the most attractive for immigration from the perspective of recent developments on the labor market.

Basing an immigration screening tool on recent labor market trends is not only more transparent and objective than forecasts of future labor market developments, but also attractive for equity reasons in the sense that groups which have lost wages/employment in the recent past are being 'protected' from immigration. Although this is not a criterion justifiable on any economic efficiency grounds, we believe it increases the political viability of our suggestion. ${ }^{1}$

Another important issue concerns the labor markets which potential immigrants would finally enter, if permitted immigration. In the approach proposed in this paper, the labor markets are defined

\footnotetext{
${ }^{1}$ A different equity criterion would select immigrants on the basis of whether they contribute to making the wage distribution more equal. This is implicit in immigration policies focussing on high-skilled immigrants. Which equity criterion is chosen depends on how one would evaluate cross-sectional wage inequality versus wage/employment losses over time. Certainly, mixtures of these criteria are possible.
} 
by the human capital characteristics of their workers. If these characteristics are partly choice variables, upon immigration the immigrant might choose to enter a different market. Generally however, the characteristics of the immigrant are indicative of the labor market likely to be entered. For example, a blue-collar worker is likely to remain in a blue-collar labor market. In addition, it is possible to tie immigrants to a certain labor market, at least in the medium run. In Switzerland, for instance, non-EU immigrants receive a so-called B permit where changes of regions as well as of employers have to be permitted by the immigration and labor market authorities. Most affected nationality groups have to remain in this status for 10 years before they receive a green card (implying free choice of regional location and of occupation).

Furthermore, the political objectives of immigration policy may extend beyond a smooth absorption of immigrants into the labor market. For example, to finance the public pension system, younger immigrants might be preferred. Finally, existing legal frameworks have to be respected which may prohibit denial of immigration permission to certain groups of persons, e.g. in the case of the EU nationals of other EU countries. Being aware of these problems, we nevertheless focus on the wage/employment loss criterion and therefore stick with recent labor market trends for our proposed immigration control tool. Even if in the case of Europe, EU regulations will allow free migration between most European countries soon, this tool will still be valuable for regulating immigration from outside of Europe, either for nation states or for a potential future European migration policy.

\section{Classification of Labor Markets}

For classifying labor markets according to net demand shifts and potential wage rigidities, we need to estimate and test whether unemployment rates and/or wages increased or decreased over time. In the following, a nonparametric approach to estimate $\Delta_{t}^{t+\tau} \mathcal{W}^{l}$ and $\Delta_{t}^{t+\tau} \mathcal{U}^{l}$ is described.

\subsection{Estimation of Expected Wages and Unemployment Risk}

Since any statistical delimitation of labor markets will imply an aggregation of several sub-markets for even more specific skills, no uniform wage is paid in these markets. Hence, within each market, wages vary due to unobserved heterogeneity. Let a labor market be delineated by a row vector of characteristics $x$, which may include, for example, age (as a proxy for experience), education, 
occupation and region. We define the 'wage' $\mathcal{W}_{t}^{l}$ in labor market $x_{l}$ as the expected value of the wage distribution in this market. Equivalently, the unemployment rate $\mathcal{U}_{t}^{l}$ in this labor market can be represented by the expected value of the unemployment incidence. We thus define

$$
\begin{aligned}
& \mathcal{W}_{t}^{l} \equiv \mathcal{W}_{t}\left(x_{l}\right) \equiv E\left[W_{t} \mid X=x_{l}\right] \\
& \mathcal{U}_{t}^{l} \equiv \mathcal{U}_{t}\left(x_{l}\right) \equiv E\left[U_{t} \mid X=x_{l}\right],
\end{aligned}
$$

where $W_{t}$ is the hourly wage rate and $U_{t}$ is a binary variable indicating whether a person is unemployed at time $t$. Accordingly, wage and unemployment changes between time $t$ and $t+\tau$ in labor market $x_{l}$ are then given by differences in the expected values as:

$$
\begin{aligned}
& \Delta_{t}^{t+\tau} \mathcal{W}\left(x_{l}\right) \equiv E\left[W_{t+\tau} \mid X=x_{l}\right]-E\left[W_{t} \mid X=x_{l}\right] \\
& \Delta_{t}^{t+\tau} \mathcal{U}\left(x_{l}\right) \equiv E\left[U_{t+\tau} \mid X=x_{l}\right]-E\left[U_{t} \mid X=x_{l}\right] .
\end{aligned}
$$

A parametric approach to estimating these expected values given a set of characteristics $x$ (the subscript $l$ is dropped henceforth) proceeds by assuming that the true conditional expectation function can be represented for all feasible $x$ by a known function, e.g. $E[W \mid X=x]=x \beta$ and an unknown but finite coefficient vector $\beta$. Estimating these coefficients $\beta$ allows predicting $E[W \mid X=x]$ for any labor market $x$ by $x \hat{\beta}$. However, these estimates will be biased if the supposed functional form is incorrect. In addition, a parametric specification can also suppress heterogeneity in the expected wages and unemployment risks among the different labor markets, see Frölich (2001). It may thus appear as if wages and unemployment vary little between different skill groups, since changes can be only due to variations in $x$ but not in $\beta$. This might pretend similar wage-unemployment developments over time for different labor markets, while they actually might have evolved very differently.

To better allow for heterogeneous (segregated) labor markets it has recently become popular in the empirical labor economics literature to split the population into a few broad labor markets and to estimate expected values by sample means separately in each market. These labor markets are often constructed by discretizing (continuous) variables such as age, experience or education into broad categories, e.g. age brackets of 20-29, 30-39, 40-49 years, and partitioning the population into a few 
cells according to combinations of age group, gender, education, experience, occupation, industry, or region. ${ }^{2}$ However, apart from the obvious loss of information through categorizing continuous regressors, such a nonparametric 'frequency estimator' is generally rather inefficient (Racine and Li, 2004). It neglects the economic links between neighboring age-education cells and does, for example, not incorporate into the estimator the well-established stylized fact that wages generally rise with education. Moreover, this analysis delivers results only for very coarsely defined and highly aggregated labor markets, which is unsatisfactory given the highly specialized and sophisticated labor markets found in modern economies. For a more disaggregated examination, however, this approach would not only be inefficient, it is often even infeasible due to the large number of cells. Even with only 10 binary labor market characteristics, $2^{10}=1,024$ different labor markets would need to be analyzed. For some of these labor markets no sample observations might be available, leaving estimates for these markets undefined. This latter problem is exacerbated if the evolution of expected values over time is examined, since this requires that the estimate is defined in all points of time.

Thus, in practice smoothing over the discrete variables is as necessary as smoothing over the continuous variables. We propose estimating expected wages and unemployment risk for specific, narrowly defined labor markets by nonparametric kernel regression, using the hybrid kernel of Racine and $\mathrm{Li}$ (2004) to accommodate discrete as well as continuous variables. Nonparametric regression on a higher-dimensional $x$ vector is still uncommon in applied econometrics, presumably because of the 'curse of dimensionality', i.e. the deterioration of the convergence rate of nonparametric estimators with the number of (continuous) regressors. However, this does not imply that nonparametric regression is less precise than (misspecified) parametric estimation, once one acknowledges that hardly ever the true form of the conditional expectation function is known. In parametric estimation any bias due to misspecification is tacitly assumed away, whereas the bandwidth selection procedures for nonparametric regression seek to balance variance and squared bias.

Nevertheless, it seems that particularly in higher-dimensional nonparametric regression not only bandwidth selection is of crucial concern but that the choice of the local extrapolation plane is important as well (Frölich, 2001). We suggest to fit a parametric model locally in the neighborhood of

${ }^{2}$ Cf. Altonji and Card, 1991; Bound and Johnson, 1992; Card, Kramarz, and Lemieux, 1999; Kahn, 2000; Katz and Murphy, 1992; Krueger and Pischke, 1997; Murphy and Welsh, 1992. 
$x$, which allows that the coefficients $\beta_{x}$ of the parametric model itself vary with $x$. In contrast to parametric regression, the specification imposed in local parametric regression is not assumed to be true but rather used to achieve more precise extrapolations around $x$. Just because data are so sparse in higher-dimensional spaces, for many labor markets no or only very few observations will be available in the immediate neighborhood, such that the estimation of $E\left[W_{t} \mid X=x\right]$ and $E\left[U_{t} \mid X=x\right]$ must rely on observations that are less nearby.

Therefore, we propose to estimate expected wages by local linear regression and unemployment risk by local logit. The expected wage for labor market $x$ in year $t$ is estimated as

$$
\hat{E}\left[W_{t} \mid X=x\right]=x \hat{\beta}_{x, t} \quad \text { with } \quad \hat{\beta}_{x, t}=\underset{\beta}{\arg \min } \sum_{i=1}^{N_{t}}\left(w_{i, t}-x_{i, t} \beta\right)^{2} \cdot K_{h_{W, t}, \lambda_{W, t}}\left(x_{i, t}-x\right)
$$

and the unemployment probability is estimated by local likelihood as

$$
\begin{aligned}
& \hat{E}\left[U_{t} \mid X=x\right]=\Lambda\left(x \hat{\gamma}_{x, t}\right) \text { with } \\
& \hat{\gamma}_{x, t}=\underset{\gamma}{\arg \max } \sum_{i=1}^{N_{t}}\left[u_{i, t} \ln \Lambda\left(x_{i, t} \gamma\right)+\left(1-u_{i, t}\right) \ln \left(1-\Lambda\left(x_{i, t} \gamma\right)\right)\right] \cdot K_{h_{U, t}, \lambda_{U, t}}\left(x_{i, t}-x\right),
\end{aligned}
$$

from a sample of observations $\left\{w_{i, t}, u_{i, t}, x_{i, t}\right\}_{i=1}^{N_{t}}$, where $w_{i, t}$ is the wage and $u_{i, t}$ the unemployment status of an individual $i$ attached to the labor market $x_{i, t}$ (according to his or her characteristics). ${ }^{3} x_{i, t}$ and $x$ are $1 \times Q$ row vectors with the first element being one, $K$ is a multidimensional kernel weighting function that attaches higher weights to observations from labor markets $x_{i, t}$ which are similar to labor market $x$ and (near) zero weights to observations from labor markets that are very dissimilar to $x . \Lambda(\omega)=e^{\omega} /\left(1+e^{\omega}\right)$ is the logit function. The coefficients $\hat{\beta}_{x, t}, \hat{\gamma}_{x, t}$ are estimated separately for each year $t$ from the sample observed in $t$, i.e. no time-invariant structures or common effects are assumed. How these estimators can be implemented in practice is further described in our companion paper (Frölich and Puhani, 2004). Nonparametric estimates obtained in this way can be used to implement the theoretical classification proposed in Section 2, as explained in the following subsection.

\footnotetext{
${ }^{3}$ Since wages are observed only for the employed, the estimated wages might be upward biased. However, as we examine differences (of expected wages) over time, potential biases are likely to largely cancel out.
} 


\subsection{Classification of Labor Markets}

With $\mathcal{W}_{t}^{l} \equiv \mathcal{W}_{t}\left(x_{l}\right), \quad \mathcal{W}_{t+\tau}^{l} \equiv \mathcal{W}_{t+\tau}\left(x_{l}\right), \quad \mathcal{U}_{t}^{l} \equiv \mathcal{U}_{t}\left(x_{l}\right)$ and $\mathcal{U}_{t+\tau}^{l} \equiv \mathcal{U}_{t+\tau}\left(x_{l}\right)$ estimated for every labor market, the labor markets can be classified on the basis of the signs of $\Delta_{t}^{t+\tau} \mathcal{W}^{l} \equiv\left[\mathcal{W}_{t+\tau}\left(x_{l}\right)-\mathcal{W}_{t}\left(x_{l}\right)\right]$ and $\Delta_{t}^{t+\tau} \mathcal{U}^{l} \equiv\left[\mathcal{U}_{t+\tau}\left(x_{l}\right)-\mathcal{U}_{t}\left(x_{l}\right)\right]$ according to Table 1 . Two-sided $t$-tests can be conducted at the 5 percent level to decide for each labor market whether the wage or the unemployment rate have increased, decreased or not changed significantly (inference procedures for the nonparametric estimates are discussed in our empirical paper, Frölich and Puhani, 2004). This implies a level of 10 percent of the Bonferroni test of the joint null hypothesis that $\Delta_{t}^{t+\tau} \mathcal{W}^{l}=\Delta_{t}^{t+\tau} \mathcal{U}^{l}=0$ and allows a classification of each labor market into one of the nine categories of Table 1.

Obviously, the classification results will depend on the level of the test, which should be chosen according to the specific policy aims. If the level of the test is reduced, more markets will be classified in category (5), for which no immigration recommendations can be made. On the other hand, with a higher level of the test, more markets will be in categories (1), (3), (7) and (9). The appropriate level depends on how the recommendations of the statistical analysis would be combined with other political considerations in a selective immigration policy. If the statistical system would be attributed a substantial weight in the immigration permission, highly significant results (i.e. a low level of the test) would be required to minimize the number of wrong decisions being made. If it acts only as an additional guidance to immigration decisions, a higher level of the test might be chosen.

\section{Conclusions}

In this paper a new approach to selective immigration policy has been proposed, which is based on classifying heterogeneous labor markets as increasing or decreasing in demand as well as according to whether they exhibit wage rigidities. The basic premise of the classification is that immigration into labor markets facing falling wages and/or rising unemployment will create more political opposition than immigration into labor markets with rising wages and/or falling unemployment. We have developed a theoretical framework to classify labor markets according to their recent wage and unemployment developments, which we suggest to estimate nonparametrically for each labor market. According to these estimates, labor markets are classified as suitable or unsuitable to immigration. 
In our view, a permanent tracking of labor markets at a detailed level by a method as presented in this paper can serve as a useful information tool to monitor immigration policies. The developed methodology has certain advantages over a point system which assigns a fixed number of 'immigration points' for certain characteristics. Unlike the point system, our nonparametric analysis allows the 'immigration virtue' of a certain trait (e.g. experience) to vary between different labor markets. It should be stressed that our approach is not less transparent than the point system, as the immigration recommendations can be disseminated to policy makers as well as potential immigrants through the internet. 


\section{References}

Altonji, J.G. and D. Card (1991): The Effects of Immigration on the Labor Market Outcomes of Lessskilled Natives, in J. Abowd and R. Freeman (eds.): Immigration, Trade, and the Labor Market, Chicago: University of Chicago Press.

Antecol, H., D.A. Cobb-Clark, amd S.J. Trejo (2001): Immigration Policy and the Skills of Immigrants to Australia, Canada, and the United States, IZA Discussion Paper No. 363, Bonn.

Bauer, T. (1998): Arbeitsmarkteffekte der Migration und Einwanderungspolitik: Eine Analyse für die Bundesrepublik Deutschland [Labor Market Effects of Migration and Immigration Policy: An Analysis for the Federal Republic of Germany], Heidelberg: Physica/Springer.

Bauer, T., M. Lofstrom, and K.F. Zimmermann (2000): Immigration Policy, Assimilation of Immigrants, and Natives' Sentiments towards Immigrants: Evidence from 12 OECD Countries, Swedish Economic Policy Review 7: 11-53.

Borjas, G.J. (1999a): The Economic Analysis of Immigration, in O. Ashenfelter and D. Card: Handbook of Labor Economics, Volume 3A, Amsterdam: Elsevier.

Borjas, G.J. (1999b): Heaven's Door, Immigration Policy and the American Economy, Princeton: Princeton University Press.

Bound, J. and G. Johnson (1992): Changes in the Structure of Wages in the 1980s: An Evaluation of Alternative Explanations, American Economic Review 82: 371-392.

Brecher R.A. and E.U. Choudri (1987): International Migration versus Foreign Investment in the Presence of Unemployment, Journal of International Economics 23: 329-342.

Card, D. (2001): Immigrant Inflows, Native Outflows, and the Local Labor Market Impacts of Higher Immigration, Journal of Labor Economics 19: 22-64.

Card, D., F. Kramarz, and T. Lemieux (1999): Changes in the Relative Structure of Wages and Employment: A Comparison of the United States, Canada, and France, Canadian Journal of Economics 32: 843-877.

Friedberg, R. and J. Hunt (1995): The Impact of Immigrants on Host Country Wages, Employment, and Growth, Journal of Economic Perspectives 9: 23-44. 
Frölich, M. (2001): Applied Higher-Dimensional Nonparametric Regression, Discussion Paper 200112, Department of Economics, University of St. Gallen.

Frölich, M. and P. Puhani (2004): Developing an Immigration Policy for Germany on the Basis of a Nonparametric Labor Market Classification, Allgemeines Statistisches Archiv - Journal of the German Statistical Society 88: 1-22.

Fuest C. and M. Thum (2000): Welfare Effects of Immigration in a Dual Labor Market, Regional Science and Urban Economics 30: 551-563.

Fuest C. and M. Thum (2001): Immigration and Skill Formation in Unionised Labour Markets. European Journal of Political Economy 17: 557-573.

Gottschalk, P. and M. Joyce (1998): Cross-National Differences in the Rise of Earnings Inequality: Market and Institutional Factors, Review of Economics and Statistics 80: 489-502.

Johnson, G. (1980): The Labor Market Effects of Immigration, Industrial and Labor Relations Review 33: $331-341$.

Kahn, L.M. (2000): Wage Inequality, Collective Bargaining, and Relative Employment from 1985 to 1994: Evidence from Fifteen OECD Countries, Review of Economics and Statistics 82: 564579.

Katz, L. and K. Murphy (1992): Changes in Relative Wages 1963-1987: Supply and Demand Factors, Quarterly Journal of Economics 107: 35-78.

Katz, L.F. and D.H. Autor (1999): Changes in Wage Structure and Earnings Inequality in: O.C. Ashenfelter and D. Card (eds.): Handbook of Labor Economics. Handbooks in Economics, Vol. 3A. Amsterdam: Elsevier, 1463-1555.

Krueger, A.B. and J-S. Pischke (1997): Observations and Conjectures on the U.S. Employment Miracle, NBER Working Paper No. 6146, Cambridge MA.

Murphy, K.M. and F. Welch (1992): The Structure of Wages, Quarterly Journal of Economics 107: 285-326.

Nickell, S. and B. Bell (1996): Changes in the Distribution of Wages and Unemployment in OECD Countries, American Economic Review Papers and Proceedings 86: 302-321.

Puhani, P.A. (2003): Relative Demand Shocks and Relative Wage Rigidities During the Rise and Fall of Swiss Unemployment, Kyklos 56: 543-564. 
Racine J. and Q. Li (2004): Nonparametric Estimation of Regression Functions with Both Categorical and Continuous Data, forthcoming in Journal of Econometrics.

Schmidt, C.M., A. Stilz, and K.F. Zimmermann (1994): Mass Migration, Unions, and Government Intervention, Journal of Public Economics 55: 185-210. 